\title{
APURAÇÃO DE CUSTO POR DEPARTAMENTO EM ESCRITORIO DE CONTABILIDADE DO MUNICIPIO DE NOVA OLIMPIA
}

\author{
Luciano Guedes de Souza ${ }^{1}$ \\ Marcelo Evandro Alves ${ }^{2}$
}

\section{RESUMO}

A apuração dos custos em uma empresa tem por objetivo identificar os gastos ocorridos para assim verificar suas necessidades de recursos, falhas gerenciais e possibilidades de economia. A departamentalização por sua vez atribui a cada setor a sua responsabilidade nos gastos gerais da empresa. O presente estudo tem por finalidade implantar e apurar os custos por departamento em escritório de contabilidade, explorar a aplicação da contabilidade de custos ao ramo de serviços e seus benefícios na gestão, as definições de cada departamento e os benefícios oriundos da departamentalização no segmento de trabalho. O principal problema do escritório está relacionado à questão de controle de seus custos, tendo em vista que o mesmo não consegue distinguir onde está sendo aplicado cada recurso. A metodologia aplicada neste estudo foi bibliográfica e estudo de caso, mostrando ao gestor a importância de se identificar como os recursos estão sendo aplicados dentro de sua empresa, onde estão sendo aplicados todos os desembolsos e por fim mostrar qual setor existe a possibilidade de uma redução de custos. O resultado atingido foi satisfatório quanto ao problema proposto apontando o setor que mais consumiu os recursos da empresa. Por fim, para a melhor visualização da empresa conseguiu-se mostrar que, tendo um melhor controle de seus custos e desembolsos o empresário consegue ter maior controle de seus gastos.

Palavras-chave: Contabilidade, Custos, Departamentalização, Serviços.

\section{INTRODUÇÃO}

A apuração dos custos em uma empresa é parte fundamental para a obtenção de resultados positivos nos dias atuais. Em virtude da alta competitividade no mercado, somente as empresas que tiverem total conhecimento de sua estrutura de desembolsos poderá oferecer serviços ou produtos a preço justo, tanto para ela quanto para o consumidor final. Segundo Martins (2003) a competitividade entre as empresas atuais, tanto industriais, comerciais ou de serviços, fez com que o gerenciamento de custos se tornasse fator determinante na tomada de decisões gerenciais.

Para tanto, é necessário que todos os setores da empresa estejam envolvidos no processo, atuando no controle dos gastos de cada área, otimizando as rotinas a fim de obter excelência em suas atividades. Diante dessa necessidade as empresas precisam dispor de ferramentas eficazes no controle de custos.

\footnotetext{
${ }^{1}$ Acadêmico do curso de Ciências Contábeis da UNEMAT - Campus de Tangará da Serra, lucianogsouza@hotmail.com

${ }^{2}$ Professor do Departamento de Ciências da UNEMAT - Campus de Tangará da Serra, marcelo.evandro@unemat.br
} 
Logo, para o desenvolvimento deste artigo levantou-se o seguinte problema: no escritório de contabilidade existem registros que permitem apurar os custos por departamento?

Desta forma, o objetivo geral deste artigo é avaliar a forma como um escritório de contabilidade de gestão familiar realiza o controle de custos em sua rotina. Como objetivo específico tem-se a definição dos departamentos e conseqüente implantação de centros de custos para cada departamento. Para Beuren (2003, p.65) "os objetivos específicos devem descrever ações pormenorizadas, aspectos específicos para alcançar o objetivo geral estabelecido."

O trabalho justifica-se pelo fato de que empresas de pequeno porte e de gestão familiar em geral não tem a visão da importância de se conhecer os custos reais de suas operações e trabalham sem planejamento, logo esta análise poderá contribuir para que outras empresas conheçam a contabilidade de custos, e apliquem as ferramentas disponíveis em suas atividades.

\section{REFERENCIAL TEÓRICO}

\subsection{Contabilidade de Custos}

A contabilidade de custos surgiu a partir da Revolução Industrial, haja visto que antes deste período existia apenas a contabilidade financeira, que atendia tranquilamente as necessidades das empresas mercantis. Com o surgimento das indústrias, tornou-se necessário mensurar o custo de produção de cada produto. De acordo com Neves (2003) com o aumento das empresas industriais após a Revolução Industrial, tornou-se problema para a contabilidade a apuração de resultados destas empresas, pois era preciso adaptar os procedimentos utilizados com as empresas comerciais.

Somente tempos mais tarde a contabilidade de custos passou a ser utilizada como ferramenta gerencial. De acordo com Martins (2003, p.21) “[...] com o conseqüente aumento da distância entre administrador e ativos e pessoas administradas, passou a contabilidade de custos a ser encarada como eficiente forma de auxílio no desempenho dessa nova missão, a gerencial". Como ferramenta gerencial, é importante determinar os custos de produção, seja de bens ou serviços, assim como apurar os custos incorridos em cada departamento da empresa. Tendo conhecimento dos custos realizados em cada departamento é possível classificá-los e também identificar casos de desperdícios ou possibilidades de economia. 
Um sistema de custos pode fornecer informações sobre os gastos de cada departamento que compõe a empresa, o que possibilita a identificação do responsável pelos gastos, assim como contribui para o controle gerencial e elaboração de orçamentos (PEREZ JR.; OLIVEIRA; COSTA, 2005).

O custeio da produção tem como finalidade também o atendimento a exigências da legislação, uma vez que os valores de estoque interferem na apuração do imposto de renda e contribuição social. Desta forma, todas as empresas devem manter a contabilidade de custos em sua escrituração fiscal.

O contribuinte que mantiver sistema de contabilidade de custo integrado e coordenado com o restante da escrituração poderá utilizar os custos apurados para avaliação dos estoques de produtos em fabricação e acabados. (Decreto-Lei 1.598/1977, Art. 14, parágrafo 1).

Caso isto não ocorra, caberá aos fiscais determinar de forma arbitrária o valor dos estoques na empresa.

Se a escrituração do contribuinte não satisfizer as condições do primeiro parágrafo, os estoques deverão ser avaliados: a) os de materiais em processamento, por uma vez e meia o maior custo das matérias-primas adquiridas no período-base, ou em $80 \%$ do valor dos produtos acabados, determinado de acordo com a alínea b; b) os dos produtos acabados, em $70 \%$ do maior preço de venda no período-base. (DecretoLei 1.598/1977, Art. 14, parágrafo 3).

Conhecer os custos de produção também se faz necessário para que seja possível controlar todos os fatos ocorridos. Para que este controle seja possível, é preciso ter base que sirva de comparação, sejam fatos passados ou previsões futuras, a fim de se verificar se os resultados estão de acordo com o esperado ou se ajustem devem ser feitos.

\subsubsection{Princípios fundamentais da contabilidade aplicados a custos}

Os princípios contábeis não são leis científicas capazes de serem provadas por meio de testes que tem origem na experiência, mas são convenções aceitas e respeitadas pelos profissionais e entidades. Segundo Martins (2003) estes princípios são geralmente aceitos para a elaboração de balanços e demonstrações de resultados, auditadas pelo fisco e pela auditoria externa. Logo, é preciso conhecer a realização, a competência, o custo histórico, a consistência, o conservadorismo, entre outros. 
São normas, por convenção, adotadas e consideradas adequadas para demonstrar o patrimônio de uma empresa e as mudanças repentinas ocorridas durante o período, e permitem que sejam efetuadas as análises das demonstrações contábeis, pois se parte da condição de padrões. De acordo com Perez Jr; Oliveira; Costa, (2005), os princípios contábeis aplicados a custos são: Entidade: a contabilidade considera apenas as operações realizadas pela empresa, não havendo confusão com as operações realizadas pelos proprietários ou outras empresas que pertençam ao grupo. Continuidade: partindo deste princípio, os critérios de avaliação patrimonial consideram uma empresa em funcionamento, sendo assim, o patrimônio é avaliado pelo custo de produção ou aquisição. Realização: este princípio determina que as receitas sejam reconhecidas no momento da venda do produto ou realização do serviço para terceiros. Competência e confrontação: no momento da identificação da receita deve-se atribuir os custos e despesas ocorridos para a realização da mesma, obtendo-se assim o resultado do período. Custo como base de valor: conforme este princípio, os ativos devem ser contabilizados por seu valor de aquisição. Denominador comum monetário: este determina que as demonstrações contábeis devem ser realizadas em moeda nacional. Uniformidade ou consistência: a empresa deve utilizar um mesmo método de demonstrações contábeis, possibilitando assim a comparação entre períodos. Relevância ou materialidade: este princípio dispensa o controle rígido de gastos com materiais de pequeno valor comparados ao gasto total, facilitando assim o trabalho da contabilização dos custos. Objetividade: segundo este princípio, todos os valores atribuídos ao custo de produção devem ser assistidos por documentos que comprovem sua origem, e critérios objetivos. Conservadorismo: os estoques devem ser valorados de acordo com o custo de aquisição dos materiais para sua produção assim como os custos ocorridos na produção em si.

\subsection{Terminologia aplicada à contabilidade de custos}

Na contabilidade de custos existem vários termos utilizados com maior frequiência, porém nem sempre são utilizados de maneira correta. Sendo assim, se torna necessário, a definição dos termos utilizados com relevância. Seguem abaixo alguns dos termos:

Gastos: É todo sacrifício financeiro com que a empresa arca para se obter um produto ou serviço, Segundo Martins (2003, p. 25) na empresa "só existe gasto no ato da passagem para propriedade da empresa do bem ou serviço, ou seja, no momento que existe o reconhecimento contábil da dívida assumida ou da redução do ativo dado em pagamento". 
Desembolsos: São todas as saídas de dinheiro, seja para liquidar dívidas já contraídas ou mesmo para os pagamentos realizados no ato da aquisição do bem ou do serviço. Desembolso é o pagamento do bem ou serviço adquirido, sendo realizado antes ou após sua posse (DUTRA 2003).

Investimentos: São os gastos realizados com bens que serão alocados nos Ativos da empresa, sendo baixados ou amortizados apenas com a venda deste bem, seu consumo, desaparecimento ou desvalorização (MARTINS 2003).

Perdas: É um gasto que ocorre contra a vontade de seu proprietário. É um gasto que ocorre sem que o objetivo seja a geração de receitas. Tudo que é perdido por acidente, ou caso de força maior ocorrida por fatores externos é considerada uma perda para a empresa (BERTI, 2002).

Despesas: Entre as terminologias existentes, encontram-se também as despesas. Entende-se que despesas são todos os sacrifícios financeiros realizados para a obtenção de receitas, porém são gastos que não estão relacionados com a produção ou realização da prestação de serviço. Segundo Dutra (2003), despesa é a parte de gasto que ocorre fora das atividades de elaboração dos bens ou serviços, ocorrendo durante a comercialização. São os bens e serviços consumidos em decorrência direta ou indireta da obtenção de receitas.

Custos: Ao contrário das despesas, os custos são os gastos realizados para a obtenção de bens ou serviços. Todos os gastos ocorridos no processo produtivo são classificados como custo, podendo este ser direto ou indireto, fixo ou variável. Custos são gastos realizados no processo de produção dos bens ou prestação de serviços. Exemplificando, no caso das indústrias, são as matérias-primas, os salários e encargos sociais dos operários, a depreciação da máquina, etc. (WERNKE, 2001).

Custos Diretos: São aqueles que podem ser facilmente identificados para um seguimento particular em consideração. Custos Diretos são aqueles que podem ser facilmente relacionados ao produto ou serviço prestados, dispensando o uso de critérios de rateio para sua alocação. (PEREZ JR; OLIVEIRA; COSTA, 2005).

Custos Indiretos: São classificados os valores que são relacionados ao produto ou serviço, porém não facilmente identificados. Segundo Leone (2000, p. 111) "Um custo é indireto quando não pode ser identificado diretamente aos seus portadores finais, isto é, aos objetos que consomem os recursos ou às atividades que geraram estes custos”. 
Custos Fixos: Ocorrem independentemente se está acontecendo ou não a produção, referindo-se a estrutura para que haja condições de execução do trabalho. Custos fixos tem como característica não serem alterados pelo volume de produção, dentre eles a depreciação, a manutenção, a folha de pagamento. (BERTÓ; BEULKE, 2005).

Custos variáveis: São os custos que ocorrem apenas quando os serviços estão sendo executados. Sendo aqueles que sofrem influência do volume produzido, quanto maior a produção maior será o seu custo e quanto menor o volume menor será o seu custo. (DUTRA, 2003).

\subsection{SISTEMAS DE CUSTEIO}

Para que as empresas possam utilizar a contabilidade de custos como ferramenta gerencial, é preciso dispor de um sistema de custeio que atenda suas necessidades, apresentando os dados relevantes e reais sobre seu processo produtivo. De acordo com Martins (2003, p.37), "Custeio significa Apropriação de Custos. Assim, existem Custeio por Absorção, Custeio Variável, ABC - Activity Based Costing, etc”.

\subsubsection{Custeio Variável.}

No método de custeio variável, são alocados ao produto ou serviço apenas os custos diretamente relacionados à sua produção ou realização. Neste caso, os outros custos realizados para a manutenção das atividades devem ser ignorados. O custeio direto ou variável é um método de apropriação gerencial, que considera apenas os custos variáveis dos produtos vendidos, separados dos custos fixos, que são considerados como despesas do período. (WERNKE, 2001).

\subsubsection{Custeio por absorção}

Adotado no Brasil pelas legislações comerciais e fiscais, o custeio por absorção, segundo Perez Jr; Oliveira; Costa, (2005) determina que todos os custos de produção devem ser alocados diretamente ao produto ou serviço prestado, e os demais gastos que incorrerem no processo, tanto os fixos como os variáveis, devem ser distribuídos entre todos os produtos por critérios de rateio. 
O custo por absorção consiste na apropriação de todos os custos de produção ao produto final, mas apenas os custos relacionados a este produto. Já os gastos relacionados a empresa como um todo, os gastos gerenciais, são distribuídos a todos os produtos ou serviços prestados (MARTINS, 2003).

\subsubsection{Custeio baseado em atividades (ABC)}

O método de Custeio Baseado em Atividades, derivado da abreviatura em inglês Activity Based Costing, tem origem na necessidade de melhorar a qualidade das informações contábeis para a tomada de decisões, principalmente as relacionadas à produtividade e o mix de produtos. (DUTRA, 2003). Este critério de custeio contempla os processos, e foi desenvolvido para que se pudesse atribuir os custos e despesas indiretas aos produtos de forma mais correta. Será atribuído ao produto ou serviço o percentual de gastos indiretos dos processos de acordo com a utilização deles para a finalização do produto ou serviço.

\subsection{DEPARTAMENTALIZAÇÃO.}

Departamentalizar uma empresa significa dividir esta empresa em setores de áreas afins, de acordo com as atividades exercidas. Segundo Martins (2003) para uma correta distribuição de custos a departamentalização é obrigatória, cada departamento pode ser dividido em vários centros de custo, sendo que os departamentos devem ser divididos em produção e de serviços. Desta forma, cada departamento terá domínio dos custos ocorridos em suas operações, cabendo ao Chefe dele administrar estes custos, cortando os desperdícios e otimizando sua aplicação.

\subsubsection{Custos nas empresas prestadoras de serviços}

Distribuir os custos em uma empresa de prestação de serviços é uma tarefa muito difícil e vem se mostrando um grande desafio para os administradores destas entidades. Conforme Perez Jr., Oliveira; Costa (2005) o significativo crescimento das empresas cujas atividades estão relacionadas a prestação de serviços é uma das características do mundo econômico atual. Muitos consultores deste setor já dizem que já na primeira década deste milênio a maioria das pessoas estará trabalhando em atividades no setor de prestação de serviços. 
Alem do mais, é preciso que os empregados prestem serviços de qualidade, uma vez que este é o "produto" que a empresa vende, porém não se pode garantir que todos os empregados prestarão serviço com o mesmo comprometimento. Para Heskett (2001 apud PEREZ JR; OLIVEIRA; COSTA, 2005, p. 339) "as empresas tem dificuldade em prestar serviços de qualidade, ressaltando que uma das razões mais importante é que serviço envolve um enorme componente humano, e é muito difícil padronizar esse componente".

\section{METODOLOGIA}

A pesquisa será desenvolvida no Escritório de Contabilidade, estabelecido na cidade de Nova Olímpia, no estado de Mato Grosso, no mês de Agosto e Setembro de 2011.

Quanto aos objetivos, a pesquisa será classificada como descritiva, porque irá trabalhar com dados que são gerados na empresa. Nesse tipo de pesquisa os fatos serão analisados, observados, classificados e interpretados, sem que o pesquisador tenha qualquer interferência, sendo que as informações serão estudadas, mão não sofrerá alterações por parte do pesquisador. (ANDRADE, 2006).

Quanto aos procedimentos técnicos, a pesquisa se classifica como bibliográfica, uma vez que se necessita de estudos em material publicado, para que possa ser construído o resultado do trabalho, em bases científicas. A pesquisa bibliográfica consiste em conhecer todas as publicações relacionadas ao objeto de estudo, sejam as publicações escritas, sejam áudios ou vídeos. (MARCONI; LAKATOS, 2007).

Ainda quanto aos procedimentos técnicos a pesquisa pode ser classificada também como um estudo de caso, em virtude de realizar-se numa única empresa, buscando o resultado do objetivo previsto. $\mathrm{O}$ estudo de caso tem como característica analisar um objeto a fundo. Tem como método o planejamento, as técnicas de coleta de dados e a análise dos dados. Neste caso a preocupação é com os acontecimentos atuais, onde não se consideram variáveis independentes. Como em outros métodos, o estudo de caso investiga um assunto seguindo procedimentos pré-definidos. (ACEVEDO; NOHARA, 2007).

Quanto aos métodos, a pesquisa utilizará a percepção, que se classifica como método dedutivo, trabalhado também sob o enfoque estatístico. A dedução é o caminho das consequiências, pois uma cadeia de raciocínio em conexão descendente, isto é, do geral para o particular, leva à conclusão. Segundo esse método, partindo-se de teorias e leis gerais, pode-se chegar à determinação ou previsão de fenômenos particulares (ANDRADE, 2006). 
O estudo utilizará também o método estatístico, em virtude da apuração de dados, valores, indicadores que interferem direto e indiretamente na atividade estudada. A técnica para a coleta dos dados será utilizada a pesquisa denominada como pesquisa de campo, uma vez que serão analisados in loco os documentos que darão origem aos dados que serão trabalhados. Esta técnica busca as informações no local onde ocorrem. (SILVA, 2003).

Quanto à análise e interpretação dos dados, que é o objeto do estudo, construído a partir do problema e objetivos específicos, com a apresentação dos resultados e a evidência destes apurados ao longo da pesquisa realizada, será descrito no capítulo que tratará dos resultados e discussões.

\section{DISCUSSÕES E RESULTADOS}

O estudo foi desenvolvido na empresa JOSE FLORES DOS SANTOS \& CIA LTDA ME, localizado na cidade de Nova Olímpia-MT, constituída em 2007. Esta empresa atua na área contábil, onde realiza todo o processo contábil necessário ao bom andamento das empresas constituídas neste município, assim como nas cidades circunvizinhas.

Para alcançar os resultados desejados, trabalhou-se os objetivos com o intuito de realizar a adequação da empresa aos mesmos. No primeiro momento foi realizada avaliação da estrutura existente no escritório, para que assim fosse possível identificar os departamentos que pudessem ser reconhecidos. Da mesma forma, buscou-se identificar o responsável por cada um dos departamentos e as funções que eles exerciam. Em seguida, foi elaborado um roteiro correto de funções que deverão ser exercidas por cada responsável. Portanto, os departamentos identificados foram nomeados e em sequiência listadas as funções de sua competência, assim como corrigidos quaisquer desvios de funções que pudessem existir.

\subsection{Divisão de Cadastro e Constituição}

\section{Atribuições:}

- Abertura, alteração de dados das empresas;

- Responsável pela atualização no Sistema da Empresa (Domínio Contábil);

- Responsável por solicitar e alterar carimbos (CNPJ e Assinaturas); 
- Encerramento de empresas; (baixa ou suspensão, informar também no sistema, para que não sejam emitidos documentos);

- Acompanhamento de registro na junta comercial, cartórios de registro, receita federal, secretaria da fazenda do estado de MT, prefeituras municipais, etc;

- Solicitação de certidões negativas - CND - de qualquer natureza;

- Parcelamentos de débitos; e impressão dos mesmos com entrega no mínimo 02 dias de antecedência, e também recalcular os mesmos quando não forem pagos na data;

- Regularização da situação fiscal das empresas junto aos órgãos públicos, municipais, estaduais e federais;

- Cadastro Geral. (Bancos, Licitações, etc);

- Contratos diversos (aluguel, arrendamento, compra x venda, comodato, etc..)

\subsection{Divisão de Contabilidade}

\section{Atribuições:}

- Assessoria contábil;

- Conciliação de todas as Contas da Contabilidade (Balancete);

- Emissão de Balancete periódico;

- Elaboração do Fechamento Contábil - Balanço Anual com Ativo e Passivo;

- Demonstrativo do Resultado do Exercício;

- Demonstrativo de Lucros Acumulados;

- Elaboração da Declaração de Imposto de Renda Anual;

- Controle do limite de distribuição dos lucros;

- Emissão dos Livros Razão e Diário Geral;

- Controle do Ativo Imobilizado - aquisições e baixas;

- Enviar declaração de IRPJ, (Lucro Presumido);

- Enviar DANS (Simples Nacional);

- Enviar o SPED FISCAL; 


\subsection{Divisão de Escrita Fiscal}

\section{Atribuições:}

- Escrituração do registro de entrada;

- Escrituração dos registros de saída;

- Escrituração de resumo de apuração do ICMS;

- Escrituração de Livro de Inventário;

- Escrituração de livro de utilização de documentos fiscais e termos de ocorrência;

- Envio da GIA eletrônica mensal de apuração de ICMS;

- Envio do arquivo SINTEGRA;

- Emissão da Guia de Recolhimento de ICMS;

- Escrituração do livro de ISS;

- Emissão da Guia de Recolhimento do ISS;

- Emissão da Guia de Recolhimento do PIS

- Emissão da Guia de Recolhimento do COFINS;

- Emissão da Guia de Recolhimento do IRPJ;

- Emissão da Guia de Recolhimento do CSLL;

- Emissão da Guia de Recolhimento do simples nacional;

- Emissão das AIDF’s eletrônicas;

- Cadastro no sistema de ECF junto a SEFAZ;

- Consultas do conta corrente fiscal das empresas periodicamente (para verificar possíveis existências de pendências seja de imposto ou de entrega de GIA, SINTEGRA);

- Comunicar os clientes que possuem débitos no sistema de conta corrente;

- Avisar os contribuintes quando existir portaria disponibilizando o parcelamento do mesmo; 
- Arquivar todo e qualquer documento da área fiscal; (ICMS, SIMPLES NACIONAL, IRPJ, CSLL, ISSQN, PIS, COFINS, ITR, DACON, DCTF, NOTAS FISCAIS DE ENTRADA, SAÍDAS, TRANSFERÊNCIAS, DEVOLUÇÃO, ETC;

- Fazer todo e qualquer recálculo referente aos impostos que acima se refere;

- Fazer o PED- Pedido Eletrônico de Escrituração Eletrônica de Dados;

- Emitir os Livros fiscais eletrônicos Anuais;

- Dar total assessória as empresas nessa área, e sanar todas as dúvidas que os clientes vierem a ter.

\subsection{Divisão de Registro -Departamento Pessoal}

\section{Atribuições}

- Emissão de recibos de pagamentos de salários (Holerite);

- Emissão de Folha de Pagamento por empresa;

- Rotina de Rescisões de Contratos de Trabalho (homologar rescisões);

- Emissão de Guia de Recolhimento de INSS, FGTS, IRRF e contribuição sindical dos (empregados e empregadores);

- Cadastro de Empregados Admitidos e Demitidos (CAGED);

- Envio da RAIS e DIRF anual;

- Informes de Rendimentos (Pró-Labore, Autônomos, P.J., Aluguéis e S/C);

- Contrato de experiência;

- Ficha Salário Família;

- Emissão de recibos de adiantamento de salários;

- Solicitação de Extrato de FGTS;

- CND- Certidões referente ao INSS e ao FGTS;

- Responsável pela organização do arquivo de Departamento pessoal ( arquivar guias, etc).

\subsection{Divisão de Registro - Departamento Financeiro}




\section{Atribuições}

- Responsável, por emitir, elaborar honorários;

- Responsável pelos pagamentos das despesas do escritório;

- Responsável pelas despesas de viagens para as cidades vizinhas;

- Responsável pela Cobrança e recebimentos, e contato com os inadimplentes, com objetivo de manter o índice de inadimplência o mais baixo possível;

- Não deixar acumular os honorários, e anotar as despesas para posterior cobrança;

- Responsável pelo pagamento das despesas de viagens para serviços nos órgãos públicos das cidades vizinha, (Sefaz, Receita Federal, Caixa Econômica Federal, Junta Comercial, etc.);

\subsection{Divisão de Protocolos e Atendimento}

\section{Atribuições}

- Entregar e protocolar todo e qualquer documento a ser entregue ao cliente, é imprescindível o protocolo, sendo este o único documento que o Escritório tem para comprovar, que entregou ao cliente na data correta e evitar atritos e discussões desnecessárias a esse respeito;

- Fazer o serviço de banco, e os serviços externos que o Escritório julgar necessário.

- Buscar notas fiscais para lançamento, uma vez que a empresa esteja impossibilitada de comparecer ao Escritório, para posterior entrega;

- Auxiliar os diversos departamentos, quando solicitado;

- Atender os telefonemas, recebimento fax entre outros;

- Atendimento ao cliente, de forma ágil, para as pessoas responsáveis;

Após a departamentalização e descrição das funções atribuídas a cada departamento, foram levantados os gastos totais do escritório de contabilidade, pegando como base o mês de Agosto de 2011.

\subsection{Gastos do Escritório - 08/2011}


Tabela 01 - Gastos Gerais do mês

\begin{tabular}{|c|l|c|}
\hline 1 & Água & 17,10 \\
\hline 2 & Energia & 534,15 \\
\hline 3 & Folha de pagamento (12 funcionários) & $12.185,00$ \\
\hline 4 & Inss & $1.041,80$ \\
\hline 5 & Fgts & 974,80 \\
\hline 6 & Domínio Sistemas & 813,79 \\
\hline 7 & Material de Escritório & $1.489,00$ \\
\hline 8 & Tonner Impressora & 320,00 \\
\hline 9 & Cartuchos & 160,00 \\
\hline 10 & Telefone Fixo & 821,34 \\
\hline 11 & Telefone Celular & 322,05 \\
\hline 12 & Manutenção de computadores & 140,00 \\
\hline 13 & Manutenção de veículos (moto) & 90,00 \\
\hline 14 & Combustíveis & 300,00 \\
\hline 15 & Despesas com viagens & 160,00 \\
\hline 16 & Material de limpeza & 103,50 \\
\hline 17 & Material Cozinha / Copa & 175,00 \\
\hline 18 & Água Mineral & 56,00 \\
\hline 19 & Serratur & 120,00 \\
\hline 20 & Correspondente fiscal & 250,00 \\
\hline 21 & Depreciação de Veículos & 100,00 \\
\hline 22 & Depreciação de máquinas/equipamentos & 433,33 \\
\hline 23 & Depreciação de móveis /utensílios & 166,66 \\
\hline 24 & $1 / 12$ provisão 13 & $1.015,42$ \\
\hline 25 & $1 / 12$ provisão de férias & $1.015,42$ \\
\hline 26 & $1 / 3$ sobre 1/12 de provisão de férias & $\mathbf{2 3 . 1 4 2 , 8 3}$ \\
\hline 27 & TOTAL & \\
\hline
\end{tabular}

Fonte: Jose Flores dos Santos \& CIA LTDA - ME

De acordo com o levantamento dos gastos no período, pode-se verificar a impossibilidade da identificação do destino e do departamento onde foram desembolsados os recursos, pois os relatórios das despesas são feitos de forma sintética, e não proporcionam boa leitura ao empresário. Sendo que o mesmo fica sem saber qual departamento esta consumindo mais recursos, e o mais importante não da uma visão para o empresário saber onde poderá repassar um eventual aumento em seus honorários.

Gráfico 01 - Custos fixos e variáveis. 


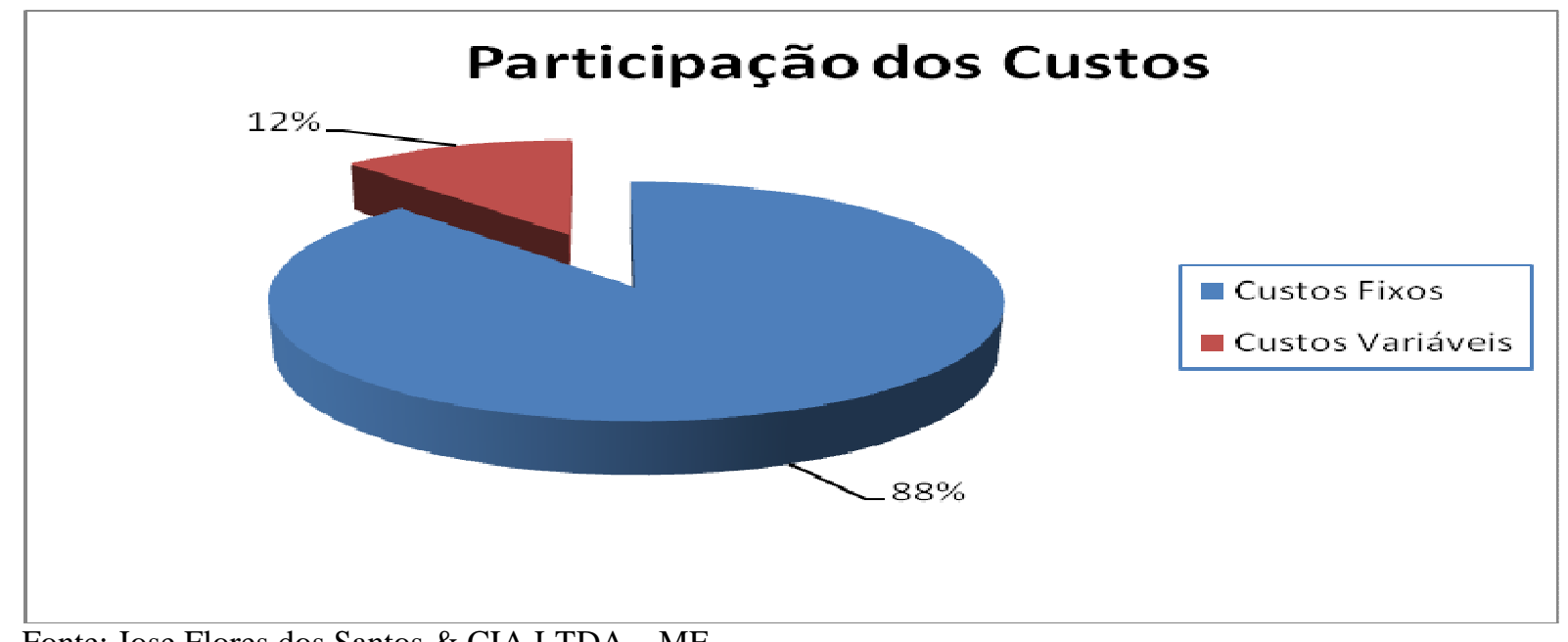

Fonte: Jose Flores dos Santos \& CIA LTDA - ME

Conforme gráfico 01 pode-se observar que os custos fixos representam 83\% dos gastos totais da empresa, enquanto os custos variáveis correspondem a $17 \%$, visto que se tratando de uma empresa de prestação de serviço, os custos fixos absorvem maior recurso da empresa.

Tabela 02 - Custos Fixos

\begin{tabular}{|c|c|c|}
\hline 1 & Água & 17,10 \\
\hline 2 & Energia & 534,15 \\
\hline 3 & Folha de pagamento (12 funcionários) & $12.185,00$ \\
\hline 4 & Inss & $1.041,80$ \\
\hline 5 & Fgts & 974,80 \\
\hline 6 & Domínio Sistemas & 813,79 \\
\hline 10 & Telefone Fixo & 821,34 \\
\hline 11 & Telefone Celular & 322,05 \\
\hline 12 & Manutenção de computadores & 140,00 \\
\hline 13 & Manutenção de veículos (moto) & 90,00 \\
\hline 16 & Material de limpeza & 103,50 \\
\hline 17 & Material Cozinha / Copa & 175,00 \\
\hline 18 & Água Mineral & 56,00 \\
\hline 21 & Depreciação de Veículos & 100,00 \\
\hline 22 & Depreciação de máquinas/equipamentos & 433,33 \\
\hline 23 & Depreciação de móveis /utensílios & 166,66 \\
\hline 24 & $1 / 12$ provisão $13^{\circ}$ & $1.015,42$ \\
\hline 25 & $1 / 12$ provisão de férias & $1.015,42$ \\
\hline 26 & $1 / 3$ sobre $1 / 12$ de provisão de férias & 338,47 \\
\hline 27 & TOTAL & $20.343,83$ \\
\hline
\end{tabular}

Fonte: Jose Flores dos Santos \& CIA LTDA - ME

Gráfico 02 - Custos fixos do mês 08/2011. 


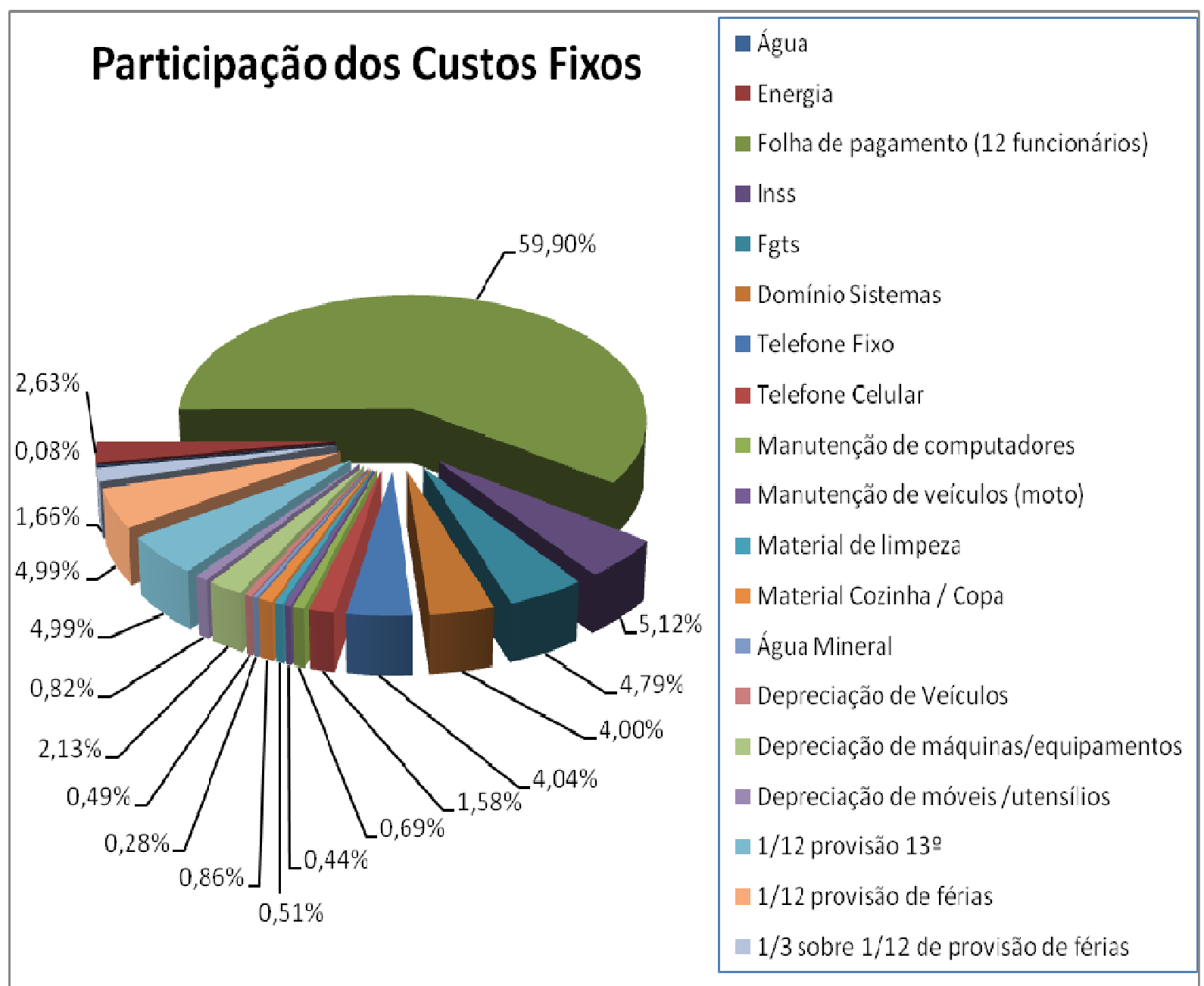

Fonte: Jose Flores dos Santos \& CIA LTDA - ME

De acordo com os dados do gráfico 02, pode-se observar que do total dos custos fixos, o que mais utiliza recursos é a folha de pagamento, correspondendo a 59,90\%, seguido dos encargos sociais referentes a folha de pagamento, INSS e FGTS, que correspondem a 5,12\% e $4,79 \%$ respectivamente. As provisões de $13^{\circ}$ e férias correspondem a 4,99\% cada e o $1 / 3$ sobre $1 / 12$ de prov. férias equivale a $1,66 \%$ do total dos custos fixos. As despesas correspondentes as contas de Telefone Fixo e Celular representam 4,04\% e 1,58\%. O pagamento da assessoria da empresa Domínio Sistemas corresponde a 4,00\%, seguido pela energia que equivale a 2,63\%. As depreciações de máquinas e equipamentos, móveis e utensílios e de veículos tem $2,13 \%, 0,82 \%$ e $0,49 \%$ de participação respectivamente. A manutenção de computadores representa $0,69 \%$ e a manutenção de veículos corresponde a $0,44 \%$ dos custos fixos. O material de limpeza consome $0,51 \%$, o material de cozinha/copa consome $0,86 \%$. A compra de água mineral consome $0,28 \%$ do total dos custos fixos e, por fim, a conta de água equivale a $0,08 \%$ desses custos.

Tabela 03 - Custos Variáveis 


\begin{tabular}{|c|l|c|}
\hline 7 & Material de Escritório & $1.489,00$ \\
\hline 8 & Tonner Impressora & 320,00 \\
\hline 9 & Cartuchos & 160,00 \\
\hline 14 & Combustíveis & 300,00 \\
\hline 15 & Despesas com viagens & 160,00 \\
\hline 19 & Serratur & 120,00 \\
\hline 20 & Correspondente fiscal & 250,00 \\
\hline 27 & TOTAL & $\mathbf{2 . 7 9 9 , 0 0}$ \\
\hline
\end{tabular}

Fonte: Jose Flores dos Santos \& CIA LTDA - ME

Gráfico 03 - Custos variáveis do mês 08/2011.

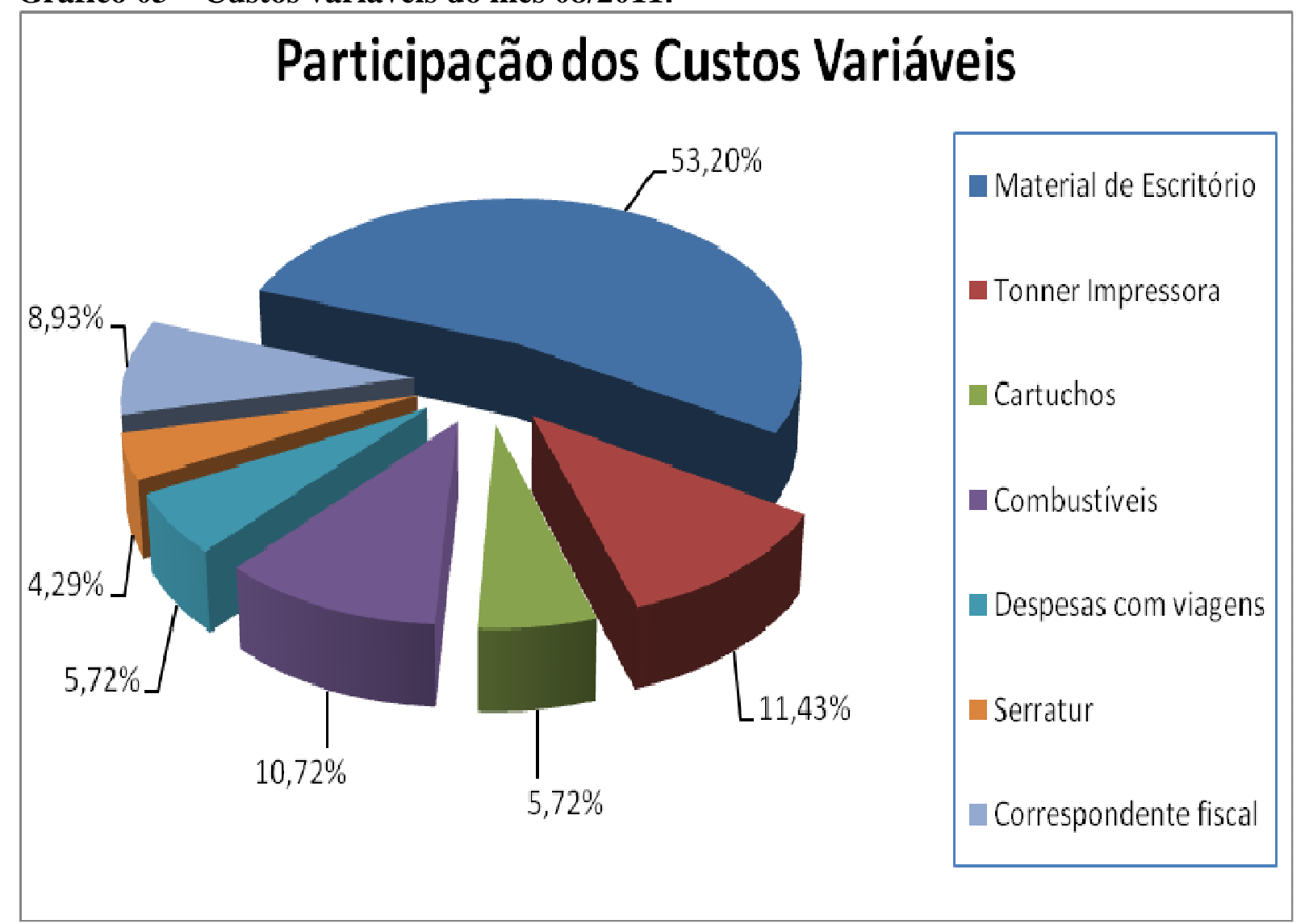

Fonte: Jose Flores dos Santos \& CIA LTDA - ME

Com base no gráfico 03, pode-se verificar que o maior representante dos custos variáveis são os desembolsos com material de escritório, equivalendo a 53,20\% destes. Os gastos com tonner da impressora representam 11,43\%, seguidos pelos gastos com combustíveis com 10,72\%. As despesas com correspondente fiscal são de 8,93\% desses custos, e os gastos com viagens e compra de cartuchos equivalem a 5,72\% cada. Por fim, os gastos com Serratur consomem 4,29\% do total dos custos variáveis. 
Tabela 04 - Alocação de custos por departamento.

\begin{tabular}{|c|c|c|c|c|c|c|}
\hline Discriminação dos Gastos & ADM/FIN & CONTABIL & CADASTRO & FISCAL & RH & PROT/ATE. \\
\hline Água & 2,85 & 1,42 & 1,42 & 4,28 & 4,28 & 2,85 \\
\hline Energia & 89,04 & 44,49 & 44,49 & 133,54 & 133,54 & 89,04 \\
\hline Folha pagamento (12uncionários) & $2.145,00$ & $1.600,00$ & 800,00 & $2.050,00$ & $4.500,00$ & $1.090,00$ \\
\hline Inss & 187,60 & 144,00 & 64,00 & 164,00 & 395,00 & 87,20 \\
\hline Fgts & 171,60 & 128,00 & 64,00 & 164,00 & 360,00 & 87,20 \\
\hline Domínio Sistemas & 135,66 & 67,79 & 67,79 & 203,45 & 203,45 & 135,66 \\
\hline Material de Escritório & 124,03 & 124,03 & 124,03 & 372,25 & 620,47 & 124,18 \\
\hline Tonner Impressora & 26,66 & 26,66 & 26,66 & 80,00 & 133,34 & 26,69 \\
\hline Cartuchos & 40,00 & & & & 120,00 & \\
\hline Telefone Fixo & 136,92 & 68,42 & 68,42 & 205,34 & 205,34 & 136,92 \\
\hline Telefone Celular & 53,69 & 26,83 & 26,83 & 80,51 & 80,51 & 53,69 \\
\hline Manutenção de computadores & 23,34 & 11,66 & 11,66 & 35,00 & 35,00 & 23,34 \\
\hline Manutenção de veículos (moto) & 15,00 & 15,00 & 15,00 & 15,00 & 15,00 & 15,00 \\
\hline Combustíveis & 75,00 & & & & & 225,00 \\
\hline Despesas com viagens & & & 48,00 & 72,00 & 40,00 & \\
\hline Material de limpeza & 17,25 & 8,62 & 8,62 & 25,88 & 25,88 & 17,25 \\
\hline Material Cozinha / Copa & 29,17 & 14,58 & 14,58 & 43,75 & 43,75 & 29,17 \\
\hline Água Mineral & 9,34 & 4,66 & 4,66 & 14,00 & 14,00 & 9,34 \\
\hline Serratur & & 30,00 & 90,00 & & & \\
\hline Correspondente fiscal & & 62,50 & 187,50 & & & \\
\hline Depreciação de Veículos & 16,67 & 16,67 & 16,67 & 16,67 & 16,67 & 16,67 \\
\hline Depreciação de máquinas/equipam. & 72,24 & 36,10 & 36,14 & 144,43 & 108,33 & 36,10 \\
\hline Depreciação de móveis/utensílios & 27,78 & 13,88 & 13,90 & 55,55 & 41,67 & 13,88 \\
\hline $1 / 12$ provisão $13^{\circ}$ & 178,75 & 133,33 & 66,67 & 170,83 & 375,00 & 90,83 \\
\hline $1 / 12$ provisão de férias & 178,75 & 133,33 & 66,67 & 170,83 & 375,00 & 90,83 \\
\hline $1 / 3$ sobre $1 / 12$ de provisão férias & 59,58 & 44,44 & 22,22 & 56,94 & 125,00 & 30,28 \\
\hline TOTAL & $3.815,91$ & $2.756,42$ & $1.889,93$ & $4.278,24$ & $7.971,21$ & $2.431,12$ \\
\hline Porcentagem de Representação & $16,49 \%$ & $11,91 \%$ & $8,17 \%$ & $18,49 \%$ & $34,44 \%$ & $10,50 \%$ \\
\hline
\end{tabular}

Fonte: Luciano Guedes de Souza

$\mathrm{Na}$ tabela acima estão descritos analiticamente os gastos atribuídos a cada departamento. Para identificação destes utilizou-se o critério de rateio por quantidade de funcionários em cada departamento, sendo que no escritório de contabilidade atualmente a 
equipe conta com 12 funcionários, que estão distribuídos em: departamento de administração e financeiro são 02 funcionários, o departamento contábil e departamento de cadastro tem 01 funcionário cada, o departamento fiscal e de recursos humanos tem 03 cada e por fim no departamento de protocolo e atendimento existem 02 funcionários.

O sistema adotado é o custeio por absorção, segundo Garrison; Noreen (2001) tanto os custos fixos ou variáveis devem ser apropriados ao produto ou serviço, visto que dessa forma é atribuído todo o custo. Além disto, este método é o aceito em vários países para elaboração de relatórios financeiros. Os custos fixos diretos foram alocados diretamente e os indiretos, tais como energia, água, telefone, material de limpeza, material de consumo entre outros, foram alocados de acordo com critério de rateio definido.

Gráfico 4 - Custos Alocados aos Departamentos.

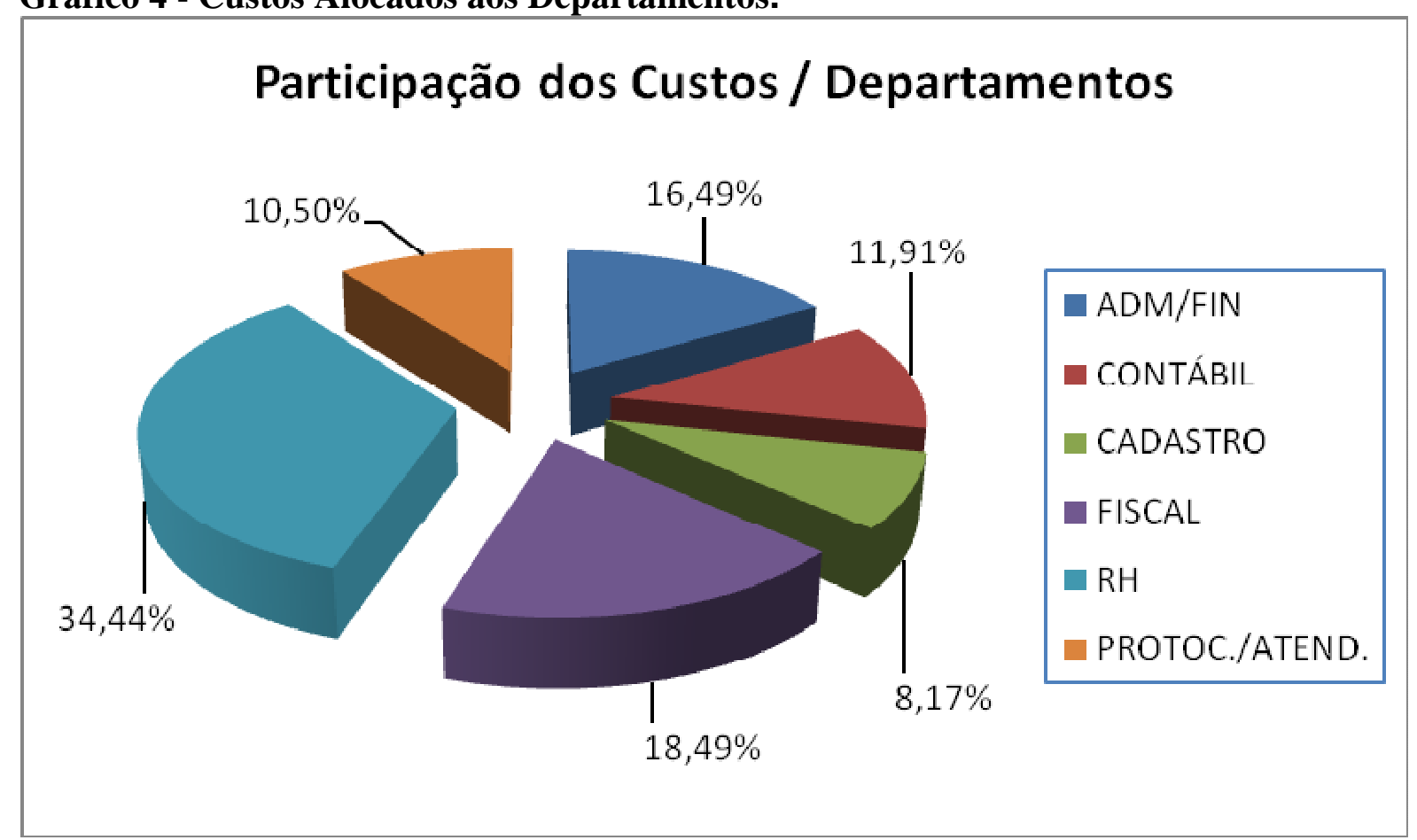

Fonte: Luciano Guedes de Souza

Nota-se no gráfico 4 que o departamento de recursos humanos é o responsável pelo maior consumo de recursos, representando $34,44 \%$ dos custos totais da empresa, seguido pelo departamento de escrita fiscal, que absorve 18,49\% desses custos. Também tem grande participação o departamento de administração e financeiro, contribuindo com a utilização de 16,49\%. Em seguida o departamento de contabilidade, que consome 11,91\% dos custos, e o departamento de protocolo e atendimento, representa o consumo de 10,50\% do total dos custos. Por ultimo, o departamento de cadastro consumiu $8,17 \%$ to total dos custos. 
Gráfico 5 - Custos fixos alocados aos departamentos.

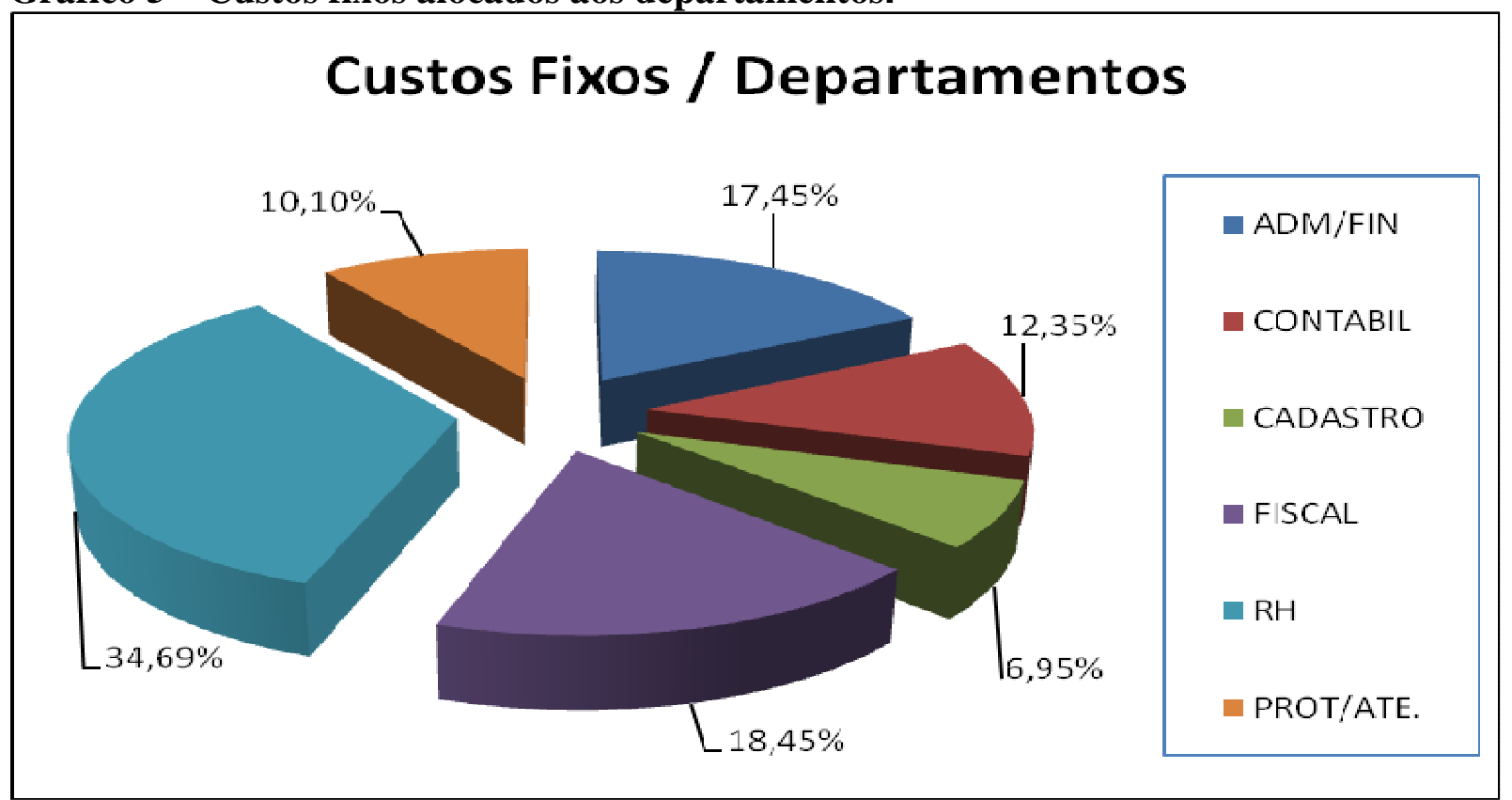

Fonte: Luciano Guedes de Souza

Analisando o gráfico 5, podemos observar a distribuição dos custos fixos pelos departamentos. O departamento de recursos humanos consome a maior parte dos gastos, com $34,69 \%$, seguido pelo departamento fiscal, com 18,45\%. O departamento de administração/financeiro corresponde a $17,45 \%$ e o contábil a 12,35\% dos custos fixos. Já o departamento de protocolo e atendimento equivale a $10,10 \%$ dos custos e, por fim, o departamento de cadastro corresponde a $6,95 \%$ do total dos custos fixos.

Gráfico 6 - Custos variáveis alocados aos departamentos.

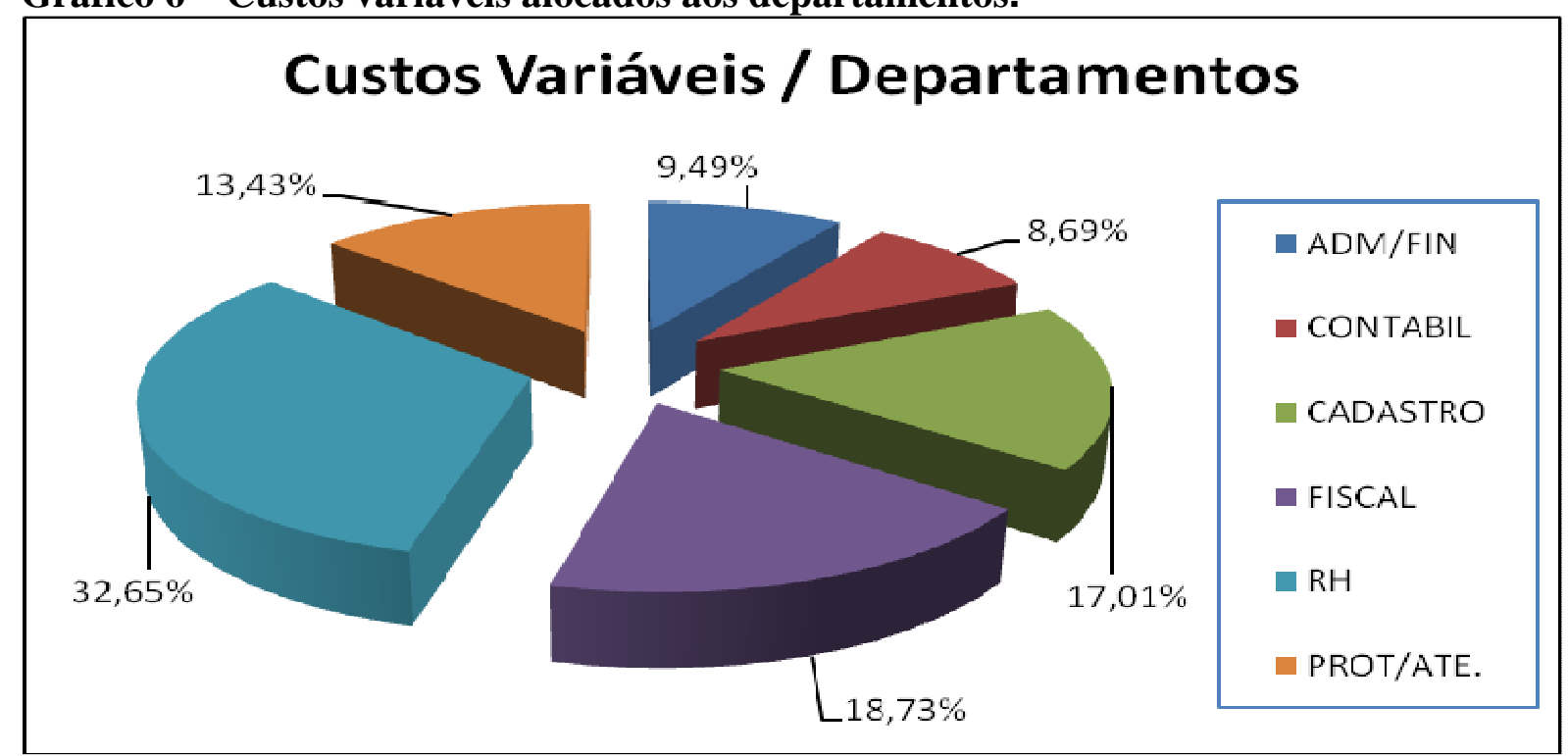

Fonte: Luciano Guedes de Souza 
O gráfico 6, demonstra a distribuição dos custos variáveis existentes na empresa por departamento. O departamento onde ocorrem os maiores gastos é o de recursos humanos, com $32,65 \%$, seguido pelo departamento fiscal, com 18,73\% do total dos custos variáveis. Já o departamento de cadastro consome $17,01 \%$ dos custos, e o departamento de protocolo e atendimento corresponde a $13,43 \%$. Em seguida o departamento administrativo e financeiro com $9,49 \%$ e por último o departamento contábil representando $8,69 \%$ do total dos custos variáveis existentes no escritório.

Tabela 05 - Analise das Receitas e Gastos do Período.

\begin{tabular}{|l|c|c|}
\hline \multicolumn{1}{|c|}{ DISCRIMINAÇÃO } & \multicolumn{2}{|c|}{ PERIODO 08/2011 } \\
\hline RECEITA & VALOR & AV \\
\hline Honorários & $37.705,32$ & $100 \%$ \\
\hline GASTOS & $\mathbf{2 3 . 1 4 2 , 8 3}$ & $\mathbf{6 1 , 3 8 \%}$ \\
\hline Administração/Financeiro & $3.815,91$ & $10,12 \%$ \\
\hline Contábil & $2.756,42$ & $7,31 \%$ \\
\hline Cadastro & $1.889,93$ & $5,01 \%$ \\
\hline Fiscal & $4.278,24$ & $11,35 \%$ \\
\hline Recursos Humanos & $7.971,21$ & $21,14 \%$ \\
\hline Protocolo/Atendimento & $2.431,12$ & $6,45 \%$ \\
\hline SALDO & $\mathbf{1 4 . 5 6 2 , 4 9}$ & $\mathbf{3 8 , 6 2}$ \\
\hline
\end{tabular}

Fonte: Luciano Guedes de Souza

As Receitas com honorários no período de Agosto de 2011 somam R 37.705,32 conforme demonstra a tabela acima, sendo que o total dos gastos representa $61,38 \%$ desse montante. Analisando a tabela 05 e fazendo uma comparação entre Gastos e Receitas, nota-se que no total de gastos, o departamento de Recursos Humanos tem a maior participação, representando 21,14\% destes ou seja, para cada $\mathrm{R} \$ 100,00$ reais de Receitas com honorários, $\mathrm{R} \$ 21,14$ foram para cobrir os gastos deste departamento. Em seguida, o departamento Fiscal corresponde a 11,35\% dos gastos. No departamento de Administração/Financeiro ocorrem $10,12 \%$ dos gastos ou seja, para cada $\mathrm{R} \$ 100,00$ recebido de honorários, $\mathrm{R} \$ 10,12$ foram para cobrir os gastos deste departamento. Já os gastos no departamento Contábil representam 7,31\% das Receitas. No Departamento de Protocolo/Atendimento ocorreram 6,45\% dos 
gastos, ou seja, para cada $\mathrm{R} \$ 100,00$ de Receitas com honorários $\mathrm{R} \$ 6,45$ foram para cobrir os gastos deste departamento. Por fim, no departamento de Cadastro incorreram 5,01\% do total de Gastos no período. Após deduzidos todos os gastos, observou-se que 38,62\% das Receitas com honorários sobraram no período, ou seja para cada $\mathrm{R}$ \$100,00 de Receitas de honorários recebidos, $\mathrm{R} \$ 38,62$ sobraram no período.

Este estudo poderá ser adotado pelo empresário em sua gestão, o que contribuirá com a avaliação permanente do desempenho de seu escritório, e possibilitará o acompanhamento do desempenho de cada departamento, atribuindo responsabilidades e cobrando resultados de acordo com planejamentos pré-estabelecidos.

Desta forma o empresário pode extrair relevantes informações do presente estudo, tendo total conhecimento da sua estrutura de custos, podendo fazer uso para determinar o valor que deverá ser cobrado pelos serviços que está prestando aos seus clientes.

\section{CONSIDERAÇÕES FINAIS}

O estudo contribuiu com o aprendizado, mas, sobretudo, proporcionou ao empresário, dono da empresa objeto do estudo, um projeto de implantação da departamentalização no seu escritório de Contabilidade. Alcançar os resultados remete para a análise da questão levantada no inicio deste trabalho, que visava verificar se no escritório não havia registros que permitiriam levantar e apurar os custos por departamento. Após o trabalho realizado, concluise que realmente o escritório apresentava certa deficiência na departamentalização dos custos, de acordo com os resultados apresentados.

Os objetivos foram todos alcançados, permitindo a apuração dos resultados descritos, primeiramente foram criados os departamentos e logo em seguida alocados os seus respectivos custos. Não apresentaram-se limitações quanto a coleta e desenvolvimento do trabalho, pois conforme exposto pode-se verificar que o departamento de recursos humanos foi o que mais utilizou dos recursos da empresa, sendo assim, o empresário tem total conhecimento dos seus desembolsos.

Quanto à sugestão para outros artigos de pesquisa, esta área é relevante e de grande aplicabilidade para os empresários, assim fica a sugestão para outras pesquisas na área de custos, pois o mesmo é de grande importância para gestão de uma empresa . 
A academia tem grande influência na formação dos profissionais, pois a constante busca de aprendizado permitirá que se estabeleça uma sociedade mais honesta e humana.

\section{REFERÊNCIAS BIBLIOGRAFICAS}

ACEVEDO, Claudia R.; NOHARA, Jouliana J. Monografia no curso de administração, guia completo de conteúdo e forma. 3. ed. São Paulo. Atlas. 2007.

ANDRADE, Maria M. de. Introdução à metodologia do trabalho cientifico. 7. ed. São Paulo. Atlas. 2006.

BEUREN, Ilse M. Como elaborar trabalhos monográficos em contabilidade: teoria e prática. São Paulo: Atlas, 2003.

BERTI, A. Custos - uma estratégia de gestão. São Paulo: Ícone, 2002.

BERTÓ, Dalvio J.; BEULKE, Rolando. Gestão de custos. São Paulo: Saraiva, 2005.

DECRETO-LEI No 1.598, DE 26 DE DEZEMBRO DE 1977, Disponível em <http://www.planalto.gov.br/ccivil_03/decreto-lei/Del1598.htm>, acesso em: 08 Set. 2011, 16:00:11.

DUTRA, René G. Custos uma abordagem prática. 5. ed. São Paulo. Atlas. 2003.

GARRISON, R. H.; NOREEN, E. W. Contabilidade gerencial. 9 ed. Rio de Janeiro: LTC, 2001.

LEONE, George Sebastião G. Custos: planejamento, implantação e controle. 3. ed. Sãa Paulo: Atlas, 2000.

MARCONI, Marina de A.; LAKATOS, Eva M. Fundamentos de metodologia científica. 6. ed. São Paulo. Atlas.2007.

MARTINS, E. Contabilidade de custos, 9. ed. São Paulo: Atlas, 2003.

NEVES, S. Contabilidade de custos, 7. ed. São Paulo: Frase, 2003. 272p; 
PEREZ JR.; J. H.; DE OLIVEIRA, L. M.; COSTA, R. G. Gestão estratégica de Custos. 4. ed. São Paulo: Atlas, 2005;

SILVA, Antonio Carlos R. da. Metodologia da pesquisa aplicada à contabilidade. 1. ed. São Paulo. Atlas. 2003.

WERNKE, R. Gestão de custos: uma abordagem prática. São Paulo: Atlas, 2001. 